\title{
VARIABILITY OF THE CONSERVED V3 LOOP TIP MOTIF IN HIV-1 SUBTYPE B ISOLATES COLLECTED FROM BRAZILIAN AND FRENCH PATIENTS
}

\section{Rejane-Maria Tomasini-Grotto ${ }^{1}$, Brigitte Montes $^{2}$, Denise Triglia ${ }^{1}$, Carla Torres- Braconi ${ }^{3}$, Juliana Aliano-Block ${ }^{3}$, Paolo} M. de A. Zanotto ${ }^{3}$, Maria- Inès de M. C. Pardini' ${ }^{1}$, Michel Segondy ${ }^{2}$

${ }^{1}$ Divisão Hemocentro, Faculdade de Medicina de Botucatu, Universidade Estadual Paulista, São Paulo, SP, Brasil; ${ }^{2}$ Departement de Biologie \& Pathologie, Laboratoire de Virologie, Centre Hospitalier Universitaire (CHU), Montpellier, France; ${ }^{3}$ Laboratório de Evolução Molecular e Bioinformatica, Instituto de Ciências Biomédicas, Universidade de São Paulo, São Paulo, SP, Brasil.

Submitted: July 24, 2009; Returned to authors for corrections: September 18, 2009; Approved: March 16, 2010.

\begin{abstract}
The diversity of the V3 loop tip motif sequences of HIV-1 subtype B was analyzed in patients from Botucatu (Brazil) and Montpellier (France). Overall, 37 tetrameric tip motifs were identified, 28 and 17 of them being recognized in Brazilian and French patients, respectively. The GPGR (P) motif was predominant in French but not in Brazilian patients (53.5\% vs 31.0\%), whereas the GWGR (W) motif was frequent in Brazilian patients $(23.0 \%)$ and absent in French patients. Three tip motif groups were considered: P, W, and non-P non-W groups. The distribution of HIV-1 isolates into the three groups was significantly different between isolates from Botucatu and from Montpellier $(P<0.001)$. A higher proportion of CXCR4-using HIV-1 (X4 variants) was observed in the non-P non-W group as compared with the $\mathrm{P}$ group $(37.5 \%$ vs $19.1 \%)$, and no $\mathrm{X} 4$ variant was identified in the $\mathrm{W}$ group $(P<0.001)$. The higher proportion of $\mathrm{X} 4$ variants in the non-P non-W group was essentially observed among the patients from Montpellier, who have been infected with HIV-1 for a longer period of time than those from Botucatu. Among patients from Montpellier, CD4+ cell counts were lower in patients belonging to the non-P non-W group than in those belonging to the $\mathrm{P}$ group $(24$ cells $/ \mu \mathrm{L}$ vs 197 cells $/ \mu \mathrm{L} ; P=0.005)$. Taken together, the results suggest that variability of the V3 loop tip motif may be related to HIV-1 coreceptor usage and to disease progression. However, as analyzed by a bioinformatic method, the substitution of the V3 loop tip motif of the subtype B consensus sequence with the different tip motifs identified in the present study was not sufficient to induce a change in HIV-1 coreceptor usage.
\end{abstract}

Key words: HIV-1; V3 loop; Genetic diversity; Brazil; France

\section{INTRODUCTION}

The human immunodeficiency virus type 1 (HIV-1) displays a high genetic variability, particularly in the envelope gene $(e n v)$ which encodes the glycoproteins gp120 and gp 41 that play a key role in virus entry into the target cells. The envelope glycoprotein gp120 consists of five variable regions (V1-V5) intercalated with five conserved regions (C1-C5). In HIV-1 subtype B, the third variable region (V3) is 35 amino acids long (6) and shows as consensus sequence 
CTRPNNNTRKSIHIGPGRAFYTTGEIIGDIRQAHC. The presence of two cysteine residues flanking the sequence leads to a disulphide-bond which results in a loop conformation. The tip of the V3 loop consists of a conserved amino acid sequence with predominance of the GPGR motif in subtype B (14). The substitution of the proline for a tryptophan creating the GWGR motif has been found in Brazilian strains (B-Br variant) $(3,11)$. This motif can alter the protein secondary structure leading to changes in viral antigenicity (16).

The V3 sequence plays a major role in virus tropism by determining which coreceptor, CXCR4 or CCR5, will be used for virus entry (19). It is also highly associated with the virus ability to induce syncitia formation in cell culture. Nonsyncytium-inducing (NSI) variants, which use CCR5 as coreceptor (R5 viruses), predominate in the asymptomatic phase, whereas syncytium-inducing (SI) variants, using CXCR4 as coreceptor (X4 viruses), emerge in advanced infected patients, preceding CD4+ cell decline and clinical worsening $(1,5,20,21)$. It has been shown that SI/X4 viruses are more cytopathic in vitro, and replicate to higher levels than NSI/R5 viruses $(15,24)$. Different coreceptor usage and switch from NSI to SI phenotype have been associated with amino acid substitutions in the V3 loop. On the basis of the V3 loop sequence, a bioinformatic tool, the position-specific scoring matrix (PSSM) was created to predict the viral phenotype (4,
$18,19)$. This tool demonstrated a high sensitivity to identify $\mathrm{X} 4$ viruses in HIV-1 subtype B isolates (17).

The aim of this study was to explore the variability of the tip motif in the V3 loop in HIV-1 subtype B strains obtained from HIV-1-infected patients in Brazil (Botucatu) and France (Montpellier), in relation with virological, immunological and clinical parameters.

\section{MATERIALS AND METHODS}

\section{Patients}

Subjects included in the study were 100 Brazilian and 86 French patients followed up in the university hospitals of Botucatu (São Paulo state, Brazil) and Montpellier (France), respectively. All these patients were infected with HIV-1 subtype B. Patients from Botucatu were HIV-1 infected patients who were tested for viral load and gave an informed consent to be included in the Viral Genetic Diversity Network (VGDN) project (http://www.lemb.icb.usp.br/vgdn/www). Patients from Montpellier were patients for which the V3 loop was sequenced to determine the $\mathrm{R} 5$ or $\mathrm{X} 4$ coreceptor tropism; most of these patients had advanced HIV-1 infection and multiple resistance to antiviral drugs and were eligible for treatment with the CCR5 inhibitor maraviroc. The characteristics of the patients are presented in Table 1.

Table 1. Demographic, virological, immunological and clinical characteristics of HIV-1 subtype B-infected patients from Botucatu and Montpellier.

\begin{tabular}{|c|c|c|c|}
\hline Characteristics & $\begin{array}{l}\text { Botucatu } \\
(\mathrm{N}=100)\end{array}$ & $\begin{array}{l}\text { Montpellier } \\
(\mathbf{N}=\mathbf{8 6})\end{array}$ & $\boldsymbol{P}$ \\
\hline Age, y [median (IQR)] & $39(34-46)$ & $44(40-50)$ & $<0.001$ \\
\hline Sex, Male $[\mathrm{N}(\%)]$ & $51(51.0)$ & $73(84.9)$ & $<0.001$ \\
\hline HIV-1 risk factors $[\mathrm{N}(\%)]$ & & & $<0.001$ \\
\hline Heterosexual & $24(24.0)$ & $11(12.8)$ & \\
\hline MSM & $26(26.0)$ & $63(73.2)$ & \\
\hline IDU & $17(17.0)$ & $6(7.0)$ & \\
\hline Transfusion/hemophilia & $6(6.0)$ & $4(4.7)$ & \\
\hline Unknown & $27(27.0)$ & $2(2.3)$ & \\
\hline Treatment $[\mathrm{N}(\%)]$ & & & 0.005 \\
\hline Naive & $9(9.0)$ & $14(16.3)$ & \\
\hline Discontinuation & $6(6.0)$ & $14(16.3)$ & \\
\hline On treatment & $85(85.0)$ & $58(67.4)$ & \\
\hline Duration of HIV-1 infection, y [median (IQR)] & $6(2-9)$ & $11[8-15]$ & $<0.001$ \\
\hline CDC stage $\mathrm{B}$ or $\mathrm{C},[\mathrm{N}(\%)]$ & $47(47.0)$ & $64(74.4)$ & $<0.001$ \\
\hline CD4+ cell count, cells/ $\mu \mathrm{L}[$ median $(\mathrm{IQR})]$ & $332(189-455)$ & $186(58-307)$ & $<0.001$ \\
\hline Viral load, log copies/mL [median (IQR)] & $2.73(1.70-4.14)$ & $4.65(4.23-5.21)$ & $<0.001$ \\
\hline
\end{tabular}




\section{HIV-1 subtyping}

HIV-1 subtyping was determined by phylogenetic analysis of pol (reverse transcriptase and protease genes) and env sequences using the NCBI genotyping program (http://www.ncbi.nlm.nih.gov/projects/genotyping/formpage.cg i). HIV-1 isolates were considered as belonging to subtype B when both pol and env sequences clustered within clade B in the phylogenetic trees.

\section{V3 loop sequencing}

V3 loop was amplified by RT-PCR on viral RNA extracted from EDTA plasma samples. PCR on DNA extracted from EDTA blood was used for patients with a low or undetectable RNA plasma viral load. Nucleic acid extraction was carried out using the QIAamp DNA or RNA Blood Mini Kit (Qiagen, Valencia, CA, USA) in Botucatu, and the MagNA Pure Compact Nucleic Acid Isolation Kit I on the MagNA Pure Compact extractor (Roche Diagnostics, Meylan, France) in Montpellier. Primers used for nested amplification were ED5 and ED12 (V1 through V5) for the first round, and ED31 and ED33 (C2 through C3) for the nested-PCR (13) in Botucatu, and P0 and P2 (V1 through V5) for the first round (25) and ES7 and ES8 (V3 through V5) for the nested PCR (13), in Montpellier. Sequencing of the nested PCR products was performed using the BigDye Terminator Cycle Sequencing Ready Reaction kit version 3.1 (Applied Biosystems), with the nested primers in separated reactions as sequencing primers. Sequences were analyzed on the ABI Prism ${ }^{\mathrm{TM}} 3100$ (Botucatu) or 310 (Montpellier) DNA Sequencer (Applied Biosystems, Foster City, CA, USA).

Sequences were analyzed with the sequence analysis program BioEdit (www.mbio.ncsu.edu/BioEdit/bioedit.html) to create contig sequence, to obtain the protein sequence in the correct frame, and to define the tip motif. Genotypic prediction of coreceptor tropism was based on the PSSM method (ubik.microslu.washington.edu/computing/pssm/) described by Jensen et al. (19). This bioinformatic tool for scoring V3 loop aminoacid sequences reliably predicts CXCR4 usage: known
R5 viruses have low scores $(<-5)$, R5X4 dual tropic viruses have intermediate scores, and X4 viruses have high scores.

\section{Relationship between tip motif sequences and coreceptor tropism}

In silico analysis of the impact of the V3 loop tip motif sequence was performed by analyzing, using PSSM, the HIV-1 subtype B V3 loop consensus sequence (GPGR tip motif) and the V3 loop sequences obtained by replacing the tip motif of the V3 consensus sequence by the different tip motifs identified in the present study.

\section{Data analysis}

Differences among groups were compared using KruskalWallis test and chi-square tests for continuous and categorical variables, respectively. Two-tailed Fisher's exact test was used for two-by-two contingency tables. All statistical tests were done by Statgraphics Plus software version 5.1 (Manugistics, Rockville, MD, USA). $\mathrm{P}<0.05$ was considered to be significant.

\section{RESULTS}

\section{V3 loop tip motif diversity}

Overall, 37 tetrameric tip motifs were identified. As shown in Table 2, the diversity in tip motif was higher in HIV1 subtype B strains from Botucatu (28 variants) than in those from Montpellier (17 variants). The GPGR (P) motif was predominant in Montpellier but not in Botucatu (53.5\% vs $31.0 \%$ ). On the other hand, the GWGR (W) motif was frequent in HIV-1 isolates from Botucatu (23.0\%) and absent in HIV-1 isolates from Montpellier. Three tip motif groups were considered: $\mathrm{P}, \mathrm{W}$, and non-P non-W groups. The distribution of HIV-1 strains into the three groups was significantly different between strains from Botucatu and from Montpellier $(P<$ 0.001), a higher proportion of strains from Botucatu (33.0\% vs $17.4 \%$ ) belonging to the non-P non-W group. 
Table 2. Tip motif distribution in HIV-1 subtype B isolates from Botucatu and Montpellier.

\begin{tabular}{|c|c|c|}
\hline Tip motif & $\begin{array}{l}\text { Botucatu } \\
(\mathrm{N}=100)\end{array}$ & $\begin{array}{c}\text { Montpellier } \\
(\mathbf{N}=86)\end{array}$ \\
\hline$P$ & $44(44.0 \%)$ & $71(82.6 \%)$ \\
\hline GPGR & 31 & 46 \\
\hline GPGK & 5 & 11 \\
\hline GPGS & 1 & 8 \\
\hline GPGQ & 4 & 3 \\
\hline GPGG & 3 & 3 \\
\hline $\mathrm{W}$ & $23(23.0 \%)$ & $0(0.0 \%)$ \\
\hline \multicolumn{3}{|l|}{ GWGR } \\
\hline Non-P non-W & $33(33.0 \%)$ & $15(17.4 \%)$ \\
\hline AGGR & 1 & 0 \\
\hline AKGR & 1 & 0 \\
\hline AMGR & 1 & 0 \\
\hline APAG & 1 & 0 \\
\hline APGK & 2 & 0 \\
\hline APGR & 3 & 4 \\
\hline APGS & 0 & 1 \\
\hline AWGR & 1 & 0 \\
\hline GAGR & 2 & 0 \\
\hline GFGR & 4 & 0 \\
\hline GGGR & 2 & 0 \\
\hline GIRK & 0 & 1 \\
\hline GIRR & 0 & 1 \\
\hline GLGQ & 0 & 1 \\
\hline GLGR & 2 & 1 \\
\hline GLRK & 0 & 1 \\
\hline GMGR & 1 & 0 \\
\hline GPKR & 1 & 0 \\
\hline GRGR & 1 & 0 \\
\hline GSGR & 0 & 1 \\
\hline GTGR & 1 & 0 \\
\hline GWKR & 1 & 0 \\
\hline GWRR & 2 & 1 \\
\hline HPGK & 0 & 1 \\
\hline HPGR & 0 & 1 \\
\hline QPGR & 0 & 1 \\
\hline RPGS & 1 & 0 \\
\hline RPRR & 1 & 0 \\
\hline RWGR & 1 & 0 \\
\hline RWGT & 2 & 0 \\
\hline SPGS & 1 & 0 \\
\hline
\end{tabular}


Relationship between tip motif and virological, 0.42).

\section{immunological and clinical parameters}

Coreceptor tropism: Nineteen (19.0\%) patients from Botucatu and $21(24.4 \%)$ patients from Montpellier were infected with a $\mathrm{X} 4$ variant $(P=0.37)$. As shown in Table 3 , the highest proportion of $\mathrm{X} 4$ variants was observed in the non-P non-W group, whereas none $\mathrm{X} 4$ variant was observed in the $\mathrm{W}$ group.

When this parameter was analysed within the two patient populations (Table 4), it was observed a significant higher proportion of $\mathrm{X} 4$ variant in the non-P non-W group among the patients from Montpellier. Among the patients from Botucatu, no X4 variants were observed in the $\mathrm{W}$ group, and the proportion of $\mathrm{X} 4$ variant was not significantly different between the $\mathrm{P}$ and non-P non-W groups $(20.4 \%$ vs $30.3 \% ; P=$
Viral load: As shown in Table 3, patients infected with group $\mathrm{W}$ viruses had lower viral loads than those infected with $\mathrm{P}$ or non-P non-W viruses. However, this difference may be explained by the lower viral load levels among patients from Botucatu as compared with patients from Montpellier. Indeed, in patients from Botucatu, there was no significant difference in viral load levels observed between the different tip motif groups (Table 4). Differences in viral load levels between the different tip motif groups were significant neither among patients from Botucatu nor among patients from Montpellier. No difference in viral load levels was observed between patients infected with R5 or X4 variants (4.18 vs $4.16 \log$ copies/mL; $P=0.81)$.

Table 3. Relationships between tip motif groups and demographic, virological, immunological and clinical characteristics of patients infected with HIV-1 subtype B.

\begin{tabular}{|c|c|c|c|c|}
\hline \multirow[b]{2}{*}{ Characteristics } & \multicolumn{3}{|c|}{ Tip motif group } & \multirow[b]{2}{*}{$\boldsymbol{P}$} \\
\hline & $\begin{array}{c}P \\
(\mathrm{~N}=115)\end{array}$ & $\begin{array}{c}W \\
(N=23)\end{array}$ & $\begin{array}{c}\text { non-P non-W } \\
(\mathrm{N}=48)\end{array}$ & \\
\hline Age, y [median (IQR)] & $43(38-50)$ & $35(31-41)$ & $40(28-45)$ & 0.005 \\
\hline Sex, Male $[N(\%)]$ & $85(73.9)$ & $9(39.1)$ & $30(62.5)$ & 0.004 \\
\hline HIV risk group [N (\%)] & & & & 0.02 \\
\hline Heterosexual & $19(16.5)$ & $6(26.1)$ & $10(20.8)$ & \\
\hline MSM & $65(56.5)$ & $4(17.4)$ & $20(41.7)$ & \\
\hline IDU & $8(7.0)$ & $7(30.4)$ & $8(16.7)$ & \\
\hline Transfusion/hemophilia & $7(6.1)$ & $1(4.4)$ & $2(4.2)$ & \\
\hline Unknown & $16(13.9)$ & $5(21.7)$ & $8(16.7)$ & \\
\hline Treatment $[\mathrm{N}(\%)]$ & & & & 0.66 \\
\hline Naive & $17(14.8)$ & $3(13.0)$ & $3(6.3)$ & \\
\hline Discontinuation & $12(10.4)$ & $2(8.7)$ & $6(12.5)$ & \\
\hline On treatment & $86(74.8)$ & $18(78.3)$ & $39(81.2)$ & \\
\hline $\begin{array}{l}\text { Duration of HIV-1 infection, y [median } \\
(\mathrm{IQR}) \text { ] }\end{array}$ & $\begin{array}{c}9.0 \\
(5.0-13)\end{array}$ & $\begin{array}{c}4.0 \\
(2.0-7.0)\end{array}$ & $\begin{array}{c}9.0 \\
(3.5-11.0)\end{array}$ & $<0.001$ \\
\hline CDC stage $\mathrm{B}$ or $\mathrm{C}[\mathrm{N}(\%)]$ & $71(61.7)$ & $10(43.5)$ & $30(62.5)$ & 0.24 \\
\hline HIV-1 X4 variant $[\mathrm{N}(\%)]$ & $22(19.1)$ & $0(0.0)$ & $18(37.5)$ & $<0.001$ \\
\hline $\begin{array}{l}\text { CD4+ cell count, cells/ } \mu \mathrm{L} \text { [median } \\
(\mathrm{IQR})]\end{array}$ & $246(125-381)$ & $378(237-540)$ & $248(89-418)$ & 0.19 \\
\hline $\begin{array}{l}\text { Viral load, log copies/mL [median } \\
\text { (IQR)] }\end{array}$ & $\begin{array}{c}4.26(3.26- \\
4.95)\end{array}$ & $2.68{ }_{4.31)}^{(1.70-}$ & 3.71 (1.74- & 0.003 \\
\hline
\end{tabular}

IQR, interquartile range; MSM, men who have sex with men; IDU, injection drug use. 
CD4+ cell count: Overall, the differences in CD4+ cell counts between patients belonging to the different tip motif groups were not significant (Table 3). However a significant difference was observed among the patients from Montpellier, with lower CD4+ cell counts in the non-P non-W group as compared with the $\mathrm{P}$ group (Table 4). A such difference was not observed among the patients from Botucatu. A relationship was observed between the level of CD4+ $\mathrm{T}$ cells and the coreceptor tropism. Indeed, CD4+ T cell counts were higher in patients infected with R5 variants than in those infected with
X4 variants (264 vs 169 cells $/ \mu \mathrm{L} ; P=0.01)$.

Clinical stage: No significant difference was observed in the proportion of patients belonging to the stages $\mathrm{B}$ or $\mathrm{C}$ among the different tip motif groups. This lack of difference was observed in both the French and Brazilian patient populations. A higher proportion of patients belonging to CDC stages $\mathrm{B}$ or $\mathrm{C}$ was observed in patients infected with $\mathrm{X} 4$ variants as compared with those infected with R5 variants, but the difference was not significant $(67.5 \%$ vs $57.5 \%, P=0.25)$.

Table 4. Relationships between tip motif groups and demographic, virological, immunological and clinical characteristics among HIV-1 subtype B-infected patients from Botucatu and Montpellier.

\begin{tabular}{|c|c|c|c|c|c|c|c|}
\hline \multirow[b]{2}{*}{ Characteristics } & \multicolumn{4}{|c|}{ Brazil } & \multicolumn{3}{|c|}{ France } \\
\hline & $\begin{array}{c}P \\
N=44\end{array}$ & $\begin{array}{c}\mathrm{W} \\
\mathrm{N}=23\end{array}$ & $\begin{array}{c}\text { non-P non-W } \\
\mathrm{N}=33\end{array}$ & $P$ & $\begin{array}{c}P \\
N=71\end{array}$ & $\begin{array}{l}\text { non-P non-W } \\
\quad \mathrm{N}=15\end{array}$ & $P$ \\
\hline Age, y, [ median (IQR)] & $\begin{array}{c}39.5 \\
(36.5-48.5)\end{array}$ & $\begin{array}{c}35.0 \\
(31.0-41.0)\end{array}$ & $\begin{array}{c}38.5 \\
34.5-44.0)\end{array}$ & 0.09 & $\begin{array}{c}44.0 \\
(39.0-50.0)\end{array}$ & $\begin{array}{c}44.0 \\
(41.0-53.0)\end{array}$ & 0.59 \\
\hline Sex, Male $[N(\%)]$ & $27(61.4)$ & $9(39.1)$ & $15(45.5)$ & 0.17 & $58(81.7)$ & $15(100)$ & 0.11 \\
\hline HIV-1 risk factors $[\mathrm{N}(\%)]$ & & & & 0.44 & & & 0.69 \\
\hline Heterosexual & $9(20.5)$ & $6(26.1)$ & $9(27.3)$ & & $10(14.1)$ & $1(6.7)$ & \\
\hline MSM & $15(34.1)$ & $4(17.4)$ & $7(21.2)$ & & $50(70.4)$ & $13(86.7)$ & \\
\hline IDU & $3(6.8)$ & $7(30.4)$ & $7(21.2)$ & & $5(7.0)$ & $1(6.7)$ & \\
\hline Transfusion/hemophilia & $3(6.8)$ & $1(4.4)$ & $2(6.1)$ & & $4(5.6)$ & $0(0)$ & \\
\hline Unknown & $14(31.8)$ & $5(21.7)$ & $8(24.2)$ & & $2(2.8)$ & $0(0)$ & \\
\hline Treatment $[\mathrm{N}(\%)]$ & & & & 0.60 & & & 0.53 \\
\hline Naive & $4(9.1)$ & $3(13.0)$ & $2(6.1)$ & & $13(18.3)$ & $1(6.7)$ & \\
\hline Discontinuation & $1(2.3)$ & $2(8.7)$ & $3(9.1)$ & & $11(15.5)$ & $3(20.0)$ & \\
\hline On treatment & $39(88.6)$ & $18(78.3)$ & $28(84.8)$ & & $47(66.2)$ & $11(73.3)$ & \\
\hline $\begin{array}{l}\text { Duration of HIV-1 infection, y } \\
\text { [median (IQR)] }\end{array}$ & $\begin{array}{c}6.0 \\
(3.5-9.5)\end{array}$ & $\begin{array}{c}4.0 \\
(2.0-7.0)\end{array}$ & $\begin{array}{c}6.0 \\
(2.0-10.0)\end{array}$ & 0.16 & $\begin{array}{c}11.0 \\
(8.0-16.0)\end{array}$ & $\begin{array}{c}10.0 \\
(9.0-13.0)\end{array}$ & 0.78 \\
\hline CDC stage B or C [N (\%)] & $19(43.2)$ & $10(43.5)$ & $18(54.5)$ & 0.57 & $52(73.2)$ & $12(80.0)$ & 0.75 \\
\hline HIV-1 X4 variant $[\mathrm{N}(\%)]$ & $9(20.4)$ & $0(0.0)$ & $10(30.3)$ & 0.02 & $13(18.3)$ & $8(53.3)$ & 0.007 \\
\hline $\begin{array}{l}\text { CD4+ cell count, cells } / \mu \mathrm{L} \\
{[\text { median }(\mathrm{IQR})]}\end{array}$ & $\begin{array}{c}312 \\
(213-455)\end{array}$ & $\begin{array}{c}378 \\
237-540)\end{array}$ & $\begin{array}{c}323 \\
(173-451)\end{array}$ & 0.95 & $\begin{array}{c}197 \\
(89-332)\end{array}$ & $\begin{array}{c}24 \\
(7.0-233)\end{array}$ & 0.005 \\
\hline $\begin{array}{l}\text { Viral load, log copies/mL } \\
\text { [median (IQR)] }\end{array}$ & $\begin{array}{c}3.23 \\
(1.70-4.23)\end{array}$ & $\begin{array}{l}2.68 \\
(1.7-4.31)\end{array}$ & $\begin{array}{c}2.48 \\
(1.70-3.99)\end{array}$ & 0.88 & $\begin{array}{c}2.73 \\
(1.70-4.14)\end{array}$ & $\begin{array}{c}3.04 \\
(1.70-4.46)\end{array}$ & 0.60 \\
\hline
\end{tabular}

IQR, interquartile range; MSM, men who have sex with men; IDU, injection drug use.

\section{Impact of the V3 loop tip motif on the coreceptor tropism}

The subtype B consensus V3 sequence was analyzed by PSSM as a R5 sequence with a score of -12.35. All the sequences obtained by susbtituting the tip motif of the consensus sequence with the different tip motifs were analyzed as R5 sequences with scores ranging from -9.04 (RPRR tip motif) to -14.06 (AWGR tip motif), the score being -13.39 for the sequence substituted with the GWGR motif of the B-Br variant.

\section{DISCUSSION}

Subtype B is the most prevalent HIV-1 subtype in western countries as well as in Southamerican countries such as Brazil 
$(3,10,22)$. GPGR is the most frequently encountered sequence at the tip of the V3 loop in HIV-1 subtype B, whereas the GPGQ sequence predominates among all the other HIV-1 strains (2). In the present study, we have investigated the variability of this tip motif among Brazilian and French patients infected with HIV-1 subtype B. The GPGR motif was highly predominant in French patients and was less frequent in Brazilian patients who showed a higher diversity in tip motif distribution.

A subtype B variant (B-Br) with the GWGR tip motif has been identified in a high proportion of patients infected with HIV-1 subtype B in Brazil and this variant has been recognized as predominant in several studies $(7,23)$. In the present study, the $\mathrm{B}-\mathrm{Br}$ variant was identified in a lower proportion $(23 \%)$ of subtype B-infected patients from Botucatu, but a similar proportion $(20 \%)$ has been reported in a study conducted in the São Paulo area (8).

The tip motif represents a target for neutralizing antibodies (26). Therefore, sequence variation in this motif may have an impact on virus infectivity and disease progression. A slower progression to AIDS has been observed in patients infected with the $\mathrm{B}-\mathrm{Br}$ variant as compared with those infected with subtype B strains harbouring the GPGR tip motif $(8,12,23)$. It has been suggested that the difference observed in disease progression could be due to an avidity of the anti-V3 antibodies greater for the GWGR than for the GPGR motif (9). In the present study however, patients from Botucatu infected with a $\mathrm{B}-\mathrm{Br}$ variant did not present significant differences in CD4+ cell count, viral load or clinical stage, as compared with those infected with the other subtype B variants. This observation might be explained by the fact that these disease progression indicators have only limited relevance in the group of patients from Botucatu which is characterized by a relative recent HIV1 infection (median, 6 years), and a high frequency $(85.0 \%)$ of treatment with highly active antiretroviral therapy. However, no X4 viruses were identified among patients infected with B$\mathrm{Br}$ variants, and it is well recognized that $\mathrm{X} 4$ viruses are associated with a rapid disease progression and a poor prognosis $(1,5,20,21)$. Therefore, the lower progression of
HIV-1 disease in patients infected with a B-Br variant observed in different studies could be, at least in part, due to a lack of X4 virus emergence in this variant population. However, this hypothesis merits further investigation at a larger scale.On the other hand, since the group of Brazilian patients includes patients that were recently infected, it cannot be excluded that the lack of $\mathrm{X} 4$ viruses associated with the $\mathrm{B}-\mathrm{Br}$ variant may be only a temporal matter. On the other hand, it was observed a significant difference in CD4+ cell count between the P group and the non-P non-W group among the patients from Montpellier but not among those from Botucatu. This difference may be explained by the higher proportion of $\mathrm{X} 4$ viruses in the non- $\mathrm{P}$ non-W group as compared with the $\mathrm{P}$ group in the patients from Montpellier. The longer duration of HIV-1 infection in patients from Montpellier, by allowing the switch from R5 to X4 viruses, may explain this difference between French and Brazilian patients. This observation suggests that, compared with subtype B strains belonging to the $\mathrm{P}$ group, those belonging to the non- $\mathrm{P}$ non-W group are more prone to switch to $\mathrm{X} 4$ viruses. Thus, patients infected with viruses belonging to the non- $\mathrm{P}$ non-W group could present an increased risk for emergence of $\mathrm{X} 4$ viruses at an advanced stage of their HIV-1 infection, and the lower CD4+ cell counts observed in the non-P non-W group of French patients might be explained by the higher cytopathogenic potential of the $\mathrm{X} 4$ viruses.

Within the non-P non-W group, the risk of emergence of $\mathrm{X} 4$ viruses might be different according to the individual tip motif sequences. However the sample sizes of the individual tip motif sequences were too small to analyse their association with coreceptor tropism.

We have analyzed the impact of the V3 tip motif sequence on the coreceptor tropism by substituting the different tip motifs identified in our patients to the tip motif of the HIV-1 subtype B V3 loop consensus sequence and by analysing these sequences using the PSSM tool. None of the tip motifs was able to induce a change in the coreceptor tropism, but substitutions with the different tip motifs led to changes in the PSSM score. This observation indicates that the tip motif 
sequence may have a real but limited impact on the virus coreceptor tropism and it might be hypothesized that the emergence of mutations leading to a switch to a $\mathrm{X} 4$ phenotype is favoured by a molecular environment involving the tip motif sequence.

The groups of Brazilian and French patients included in the present study were very different in terms of demographic, epidemiologic, genetic, clinical and therapeutic characteristics. This population heterogeneity could introduce a bias, and thus caution must be taken in comparing the two patient groups. However, the relationships between tip motif and biological or clinical parameters were analyzed within each patient group, and a relationship was found between the tip motif and the coreceptor tropism in both Brazilian and French patients. Therefore, the results indicate that genetic diversity in the tip motif might be related to the capacity of HIV-1 to switch from R5 to X4 phenotype. Analysis of the HIV-1 strains from Botucatu indicates that, compared to group $\mathrm{P}$ viruses, those displaying the GWGR motif seem to be protected against switch to a $\mathrm{X} 4$ phenotype, whereas analysis of HIV-1 strains from Montpellier suggests that compared to group $\mathrm{P}$ viruses, those displaying a non-P non-W tip motif seem to be at higher risk for switching to a $\mathrm{X} 4$ phenotype.

In summary, diversity in the V3 loop tip motif of HIV-1 subtype B was higher in Brazilian than in French patients. Genetic variability in this short motif might be related to viral pathogenicity and disease progression. Genetic diversity in the V3 loop tif motif and its possible clinical implication merit to be further investigated in the other HIV-1 subtypes and recombinant forms.

\section{ACKNOWLEDGEMENTS}

This research received partial support from the BrazilFrance Cooperation Program (ANRS/Programa Nacional de DST/AIDS).

\section{REFERENCES}

1. Berger, E.A.; Murphy, P.M.; Farber, J.M. (1999). Chemokine receptors as HIV-1 coreceptors: roles in viral entry, tropism, and disease. Annu.
Rev. Immunol. 17, 657-700.

2. Blouin, J.C.; Guzman, E.A.; Foley, T.B. (1996). Global variation in the HIV-1 V3 region. In: Myers, G.; Korber, B.; Foley, B.; Jeang, K.T.; Mellors, J.W.; Wain-Hobson, S. (eds) Human retroviruses and AIDS: a compilation and analysis of nucleic acid and amino acid sequences. Los Alamos National Laboratory, Los Alamos, New Mexico; 1996. p. 77201.

3. Bongertz, V.; Bou-Habib, D.C.; Brigido, L.F.M.; Caseiro, M.; Chequer, P.J.; Couto-Fernandez, J.C.; Ferreira, P.C.; Galvão-Castro, B.; Greco D, Guimarães, M.L.; Linhares de Carvalho, M.I.;., Morgado, M.G.; Oliveira, C.A.; Osmanov ,S.; Ramos, C.A.; Rossini, M.; Sabino, E.; Tanuri, A.; Ueda, M. (2000). HIV-1 diversity in Brazil: genetic, biologic, and immunologic characterization of HIV-1 strains in three potential HIV vaccine evaluation sites. Brazilian Network for HIV Isolation and Characterization. J. Acquir. Immune Defic. Syndr. 23, 184-193.

4. Brumme, Z.L.; Dong, W.W.; Yip, B.; Wynhoven, B.; Hoffman, N.G.; Swanstrom, R.; Jensen, M.A.; Mullins, J.I.; Hogg, R.S.; Montaner, J.S.; Harrigan, P.R. (2004). Clinical and immunological impact of HIV envelope V3 sequence variation after starting initial triple antiretroviral therapy. AIDS 18,F1-F9.

5. Callaway, D.S.; Ribeiro, R.M.; Nowak, M.A. (1999). Virus phenotype switching and disease progression in HIV-1 infection. Proc. Biol. Sci. 266, 2523-2530.

6. Cann, A.J.; Churcher, M.J.; Boyd, M.; O'brien, W.; Zhao, J.Q.; Zack, J.; Chen, I.S. (1992). The region of envelope gene of human immunodeficiency virus type 1 responsible for determination of cell tropism. J. Virol. 66, 305-309.

7. Casseb, J.; Hong, M.A.; Gonsalez, C.; Brigido, L.F.; Duarte, A.J.; Michael-Hendry, R. (1998). Two variants of HIV-1 B serotype are transmitted heterosexually in São Paulo, Brazil. Braz. J. Med. Biol. Res. 31, 1243-1246.

8. Casseb, J.; Komninakis, S.; Abdalla, L.; Brigido, L.F.; Rodrigues, R.; Araujo, F.; Veiga, A.P.; de Almeida, A.; Flannery, B.; Hendry, R.M.; Duarte, A.J. (2002). HIV disease progression: is the Brazilian variant subtype B' (GWGR motif) less pathogenic than US/European subtype B (GPGR)? Int. J. Infect. Dis. . 6, 164-169.

9. Casseb, J.; Montanheiro, P.; Komninakis, S.; de Brito, A.; Duarte, A.J. (2004). Human immunodeficiency virus type 1 Brazilian subtype B variant showed an increasing avidity of the anti-V3 antibodies over time compared to the subtype B US/European strain in São Paulo, Brazil. Mem. Inst. Oswaldo Cruz 99, 69-71.

10. Couto-Fernandez, J.C.; Janssens, W.; Heyndrickx, L.; Motte, J.; Fransen, K.; Peeters, M.; Delaporte, E.; Galvão-Castro, B.; Piot, P.; van der Groen, G. (1994). Genetic and antigenic variability of HIV type 1 in Brazil. AIDS. Res. Hum. Retroviruses 10, 1157-1163.

11. Covas, D.T.; Biscaro, T.A.; Kashima, S.; Duarte, G.; Machado, A.A. (1998). High frequency of the GWG (Pro Trp) envelope variant of HIV-1 in southeast Brazil. J. Acquir. Immune Defic. Syndr. 19, 74-79.

12. De Brito, A.; Komninakis, S.C.; Novoa, P.; de Oliveira, R.M.; Fonseca, 
L.A.; Duarte, A.J.; Casseb, J. (2006) Women infected with HIV type 1 Brasilian variant, subtype B (B'-GWGR motif) have slower progression to AIDS, compared with patients infected with subtype B (B-GPGR motif). Clin. Infect. Dis. 43, 1476-1481.

13. Delwart, E.L.; Herring, B.; Rodrigo, A.G.; Mullins, J.I. (1995). Genetic subtyping of human immunodeficiency virus using a heteroduplex mobility assay. PCR methods Appl. 4: S202-S216.

14. Foley, B.; Korber, B. (1992). Global variation in the HIV-1 V3 region. In: Myers, G.; Korber, B.; Hahn, B.H.; Jeang, K.T.; Mellors, J.W.; McCutchan, F.E.; Henderson LE, Pavlakis GN (eds), Human retroviruses and AIDS. Los Alamos National Laboratory, New Mexico. p 77-108.

15. Fouchier, R.A.; Meyaard, L.; Brouwer, M.; Hovenkamp, E.; Schuitemaker, H. (1996). Broader tropism and higher cytopathicity for CD4+ T cells of a syncytium-inducing compared to a non-syncytiuminducing HIV-1 isolate as a mechanism for accelerated CD4+ T cell decline in vivo. Virology 219, 87-95.

16. Galvão-Castro, B.; Couto-Fernandez, J.C.; Mello, M.A.; Linhares de Carvalho, M.I.; Castello-Branco, L.R.; Bongertz, V.; Ferreira, P.C.; Morgado, M.; Sabino, E.; Tanuri, A. (1996). A nationwide effort to systematically monitor HIV-1 diversity in Brazil: preliminary results. Brazilian Network for the HIV-1 Isolation and Characterization. Mem. Inst. Oswaldo Cruz 91, 335-338.

17. Garrido, C.; Roulet, V.; Chueca, N.; Poveda, E.; Aguilera, A.; Skrabal, K.; Zahonero, M.; Carlos, S.; Garcia,F.; Faudon, J.C.; Soriano, V.; de Mendoza, C. (2008). Evaluation of eight different bioinformatics tools to predict viral tropism in different human immunodeficiency virus type 1 subtypes. J. Clin. Microbiol. 46, 887-891.

18. Jensen, M.A.; Coetzer, M.; van't Wout, A.B.; Morris, L.; Mullins, J.I.; (2006). A reliable phenotype predictor for human immunodeficiency virus type 1 subtype C based on envelope V3 sequences. J. Virol. 80, 4698-4704.

19. Jensen, M.A.; Li, F.S.; van't Wout, A.B.; Nickle, D.C.; Shriner, D.; He,
H.X.; McLaughlin, S.; Shankarappa, R.; Margolick, J.B.; Mullins, J.I. (2003). Improved coreceptor usage prediction and genotypic monitoring of R5-to-X4 transition by motif analysis of human immunodeficiency virus type 1 env V3 loop sequences. J. Virol. 77, 13376-13388.

20. Koot, M,; van Leeuwen, R.; de Goede, R.E.; Keet, I.P.; Danner, S.; Eeftinck Schattenkerk, J.K.; Reiss, P.; Tersmette, M.; Lange, J.M.; Schuitemaker, H. (1999). Conversion rate towards a syncytium-inducing (SI) phenotype during different stages of human immunodeficiency virus type 1 infection and prognostic value of SI phenotype for survival after AIDS diagnostic. J. Infect. Dis. 179, 254-258.

21. Kupfer, B.; Kaiser, R.; Rockstroh, J.K.; Matz, B.; Schneweis, K.E. (1998). Role of HIV-1 phenotype in viral pathogenesis and its relation to viral load and CD4+ T cell count. J. Med. Virol. 56, 259-263.

22. Louwagie, J.; Delwart, E.L.; Mullins, J.I.; McCutchan, F.E.; Eddy, G.; Burke, D.S. (1994). Genetic analysis of HIV-1 isolates from Brazil reveals presence of two distinct genetic subtypes. AIDS Res. Hum. Retroviruses 10, 561-567.

23. Santoro-Lopes, G.; Harrison, L.H.; Tavares, M.D.; Xexéo, A.; Dos Santos, A.C.; Schechter, M. (2000). HIV disease progression and V3 serotypes in Brazil: is B different from B'? AIDS Res. Hum. Retroviruses $16,953-958$

24. Van't Wout, A.B.; Blaak, H.; Ran, L.J.; Brouwer, M.; Kuiken, C.; Schuitemaker, H. (1998). Evolution of syncytium inducing and nonsyncytium inducing biological virus clones in relation to replication kinetics during the course of HIV-1 infection. J. Virol. 72, 5099-5107.

25. Wang, N.; Zhu, T.; Ho, D.D. (1995). Sequence diversity of V1 and V2 domains of gp120 from human immunodeficiency virus type 1: lack of correlation with viral phenotype. J. Virol. 69, 2708-2715.

26. Zolla-Pazner, S.; Zhong, P.; Revesz, K.; Volsky, B.; Williams, C.; Nyambi, P.; Gorny, M.K. (2004). The cross-clade neutralizing activity of a human monoclonal antibody is determined by the GPGR V3 motif of HIV type 1. AIDS Res. Hum. Retroviruses 20, 1254-1258. 